УДК 621.838(03)

Драган А.П., Гороть Є.В.

DOI: https://doi.org/10.36910/6775-2313-5352-2019-14-11

ВП НУБіП України «Бережанський агротехнічний інститут»

\title{
ТИСК КОЛОДОК НА ГАЛЬМІВНИЙ ШКІВ В КОЛОДКОВИХ І СТРІЧКОВО-КОЛОДКОВИХ ГАЛЬМАХ
}

В даній статті проведено уточнення величини нормальних тисків колодки на гальмівний шків $i$, отже, величину гальмівного моменту колодкових $i$ стрічково-колодкових гальм. Отримано рівняння для визначення гальмівного моменту для різних видів гальм і проведено порівняння результатів розрахунку гальмівного моменту отриманих за нормативними формулами та за формулами отриманими в результаті проведених досліджень.

Ключові слова: Колодкове гальмо, гальмівний шків, гальмівний момент.

Вступ. Гальмівні механізми $€$ невід'ємною, найбільш відповідальною частиною вантажопідіймальних машин, що призначені для зупинки, обмеження швидкості та утримання у зваженому стані вантажу. Високі вимоги до гальмівних механізмів забезпечують безаварійну експлуатацію вантажопідіймальних машин. Гальмування швидкості вантажопіднімальних механізмів $\epsilon$ наслідком створення значних сил тертя між шківами або дисками, що обертаються, та нерухомими елементами (колодками, стрічками, дисками тощо). Під час гальмування кінетична енергія рухомих мас i елементів підіймального механізму перетворюється на теплову, що спричиняє нагрівання складових частин гальм. Існує багато типів гальм, які можна класифікувати за такими ознаками [4]:

напрямом дії зусиль натискання на гальмівний елемент 3 радіальним і осьовим замиканням;

конструкцією робочого елемента - колодкові; стрічкові, дискові, конічні тощо;

джерелом створення зусилля - ручне, пружинне, вантажне, гідравлічне, пневматичне, електричне, комбіноване і т.д.

призначенням - стопорне (для зупинки) і обмежуюче швидкість (регулятори швидкості);

принципом дії - автоматичні і керовані оператором;

характером дії приводного зусилля - закритого типу (постійно загальмовані, що розгальмовуються тільки на період виконання певної операції), відкритого типу (загальмовуються тільки для зупинки механізму) та комбіновані (можуть працювати як в закритому, так і у відкритому режимах).

Від стану і надійності їх роботи значною мірою залежить безаварійність і якість проведення спуско- підіймальних операцій.

Постановка проблеми. У зв'язку зі збільшенням мас механізмів і машин, швидкостей, частот гальмувань постає необхідність підвищення точності розрахунків деталей і вузлів як машин в цілому, так і гальм. Останні зменшують швидкість машин з заданим уповільненням або зупиняють їх на певному гальмівному шляху, а в підйомно - транспортних машинах утримують вантаж в підвішеному стані при певному коефіцієнті запасу гальмування.

Аналіз останніх досліджень і публікацій. Основам конструювання, проектування та дослідження гальмівних пристроїв присвячені роботи таких вчених: Бондаренко Л.Н. [6], Вольченко М.О., Вольченко Д.О [5], та інших. Не зважаючи на значну кількість наукових праць, які присвячені даній проблематиці питання точності розрахунку гальмівного моменту дослідженні не достатньо, і не завжди відповідають сучасним вимогам.

Мета статті. Уточнити величини нормальних тисків колодки на гальмівний шків i, отже, величину гальмівного моменту колодкових і стрічково-колодкових гальм.

Матеріал досліджень. Спочатку розглянемо задачу про навантаження рівномірно розподілені по дузі кола (рис.1).

1. Це завдання розглянуто в деяких підручниках з теоретичної механіки [1] і опору матеріалів [2], тому коротко наведемо його рішення для викладу поставленого завдання.

Сума проекцій сил $P$ на вісь $O Y$ внаслідок симетрії щодо осі $O X$, дорівнює нулю, і тому їх рівнодіюча спрямована уздовж осі $O X$. 


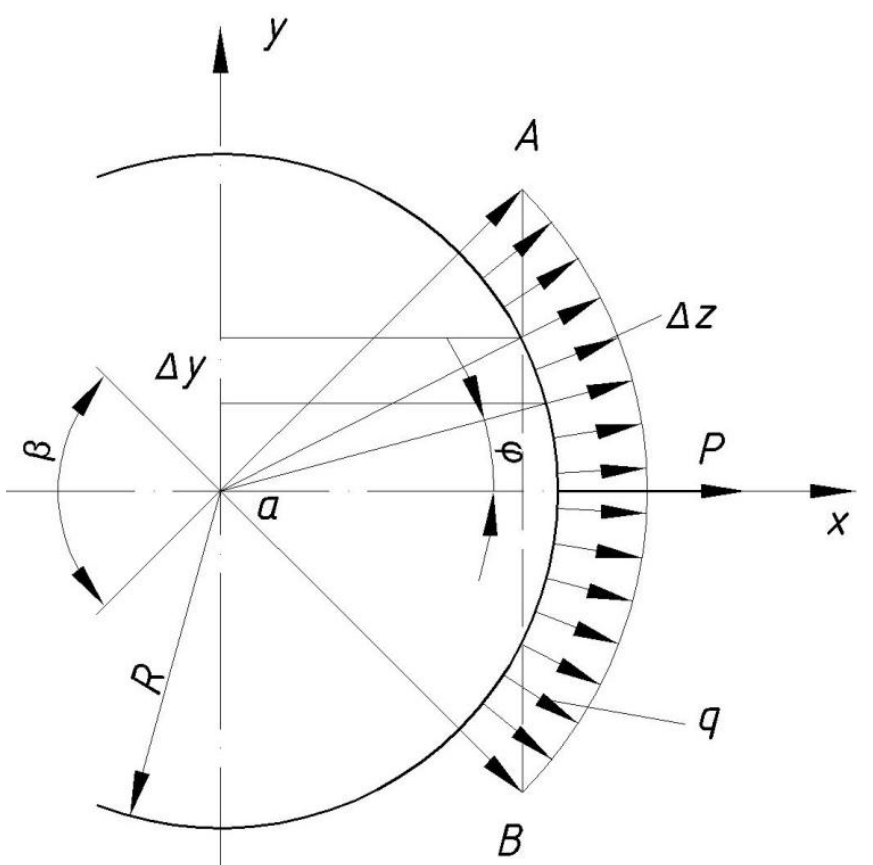

Рис.1. Сили, рівномірно розподілені по довжині дуги кола

По модулю $P=P_{X}=\Sigma q \cdot \Delta l \cdot \cos \varphi$, де $q \Delta l$ - сила, що діє на елемент дуги довжиною $\Delta l ; \varphi$ кут утворений цією силою з віссю ОХ, оскільки $\Delta l \cos \varphi=\Delta y$, то $P=q \cdot \Sigma y=q \cdot A B$, тобто $P=q \cdot h$, де $h$ - довжина хорди дуги $A B, h=2 \cdot R \cdot \sin \beta / 2$. Як бачимо, на відміну від завдань, розглянутих нижче тут присутня довжина хорди дуги.

2. При розрахунку колодкових гальм використовується сила притиснення колодки до шківа $P$. Природно, що для розрахунку величини гальмівного моменту, відповідно до закону тертя ковзання, необхідно знати як величину нормальної розподіленої сили $q$, так і її суму.

Тому, необхідно вирішити задачу зворотню до попередньої (рис. 2).

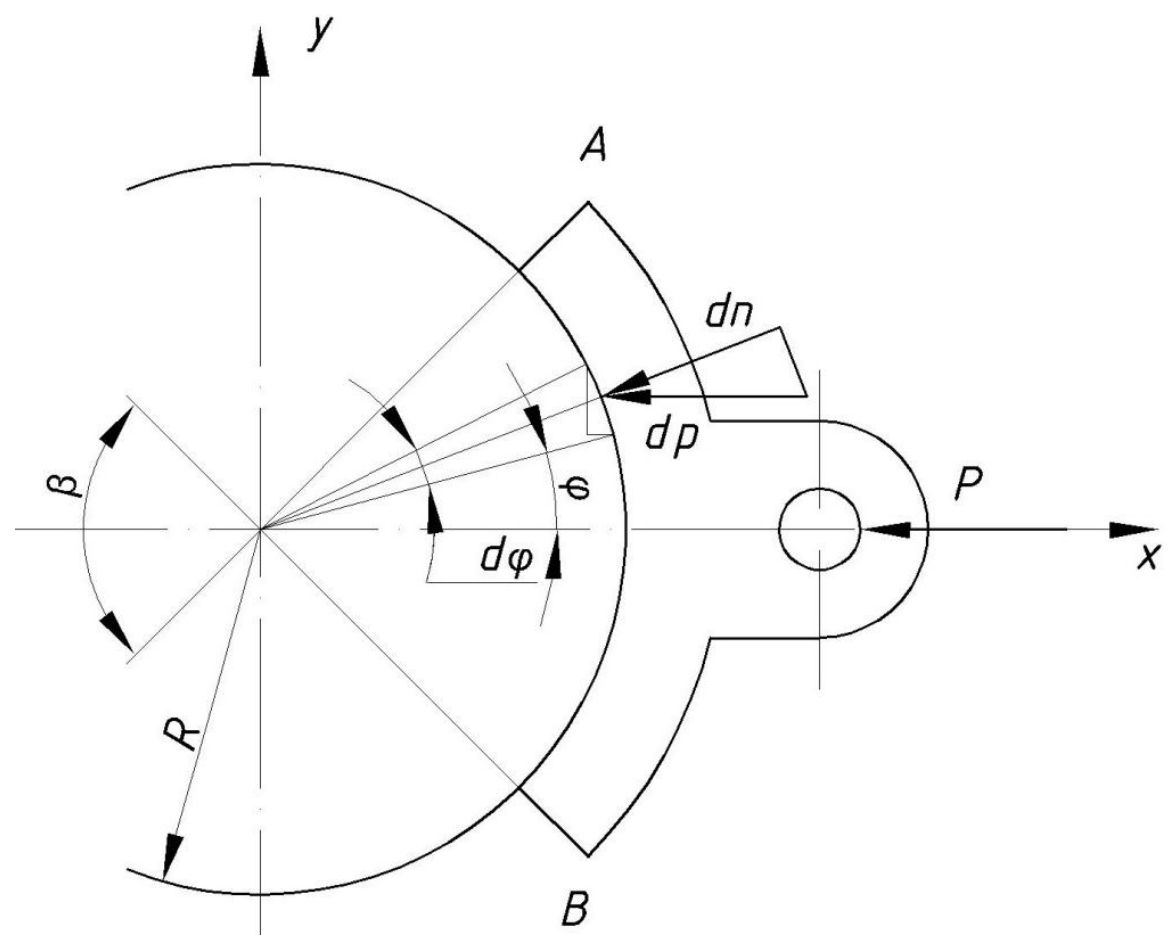

Рис. 2. До визначення нормальних тисків гальмівної колодки на шків.

Елементарна сила, що діє на вісь у елемента дуги довжиною $R d \varphi$ :

$$
d p=\frac{P}{\beta} \cdot d \beta,
$$


нормальна до нього сила

$$
d n=d p \cdot \cos \varphi=P / \beta \cdot \cos \varphi \cdot d \varphi .
$$

Загальна нормальна сила, що діє на циліндр:

$$
N=P / \beta \cdot \int_{-\frac{\beta}{2} \beta}^{+\frac{\beta}{2}} \cos \varphi \cdot d \varphi=2 P / \beta \cdot \sin \beta / 2 .
$$

Виходячи $з$ цього, гальмівний момент, що розвивається двоколодковим гальмом повинен визначатися з виразу:

$$
M_{\text {Тд }}=4 P \cdot f \cdot \frac{R}{\beta} \cdot \sin \frac{\beta}{2} .
$$

Оскільки в колодкових гальмах $60 \leq \beta \leq 120$, то необхідно оцінити точність формул (4) $\mathrm{i}$ нормативної $M_{T}=2 \cdot P \cdot f \cdot R[3,4]$.

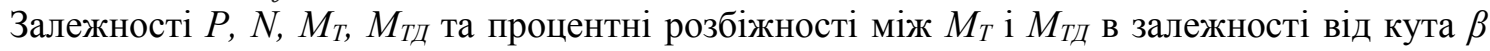
показані на рис. 3.

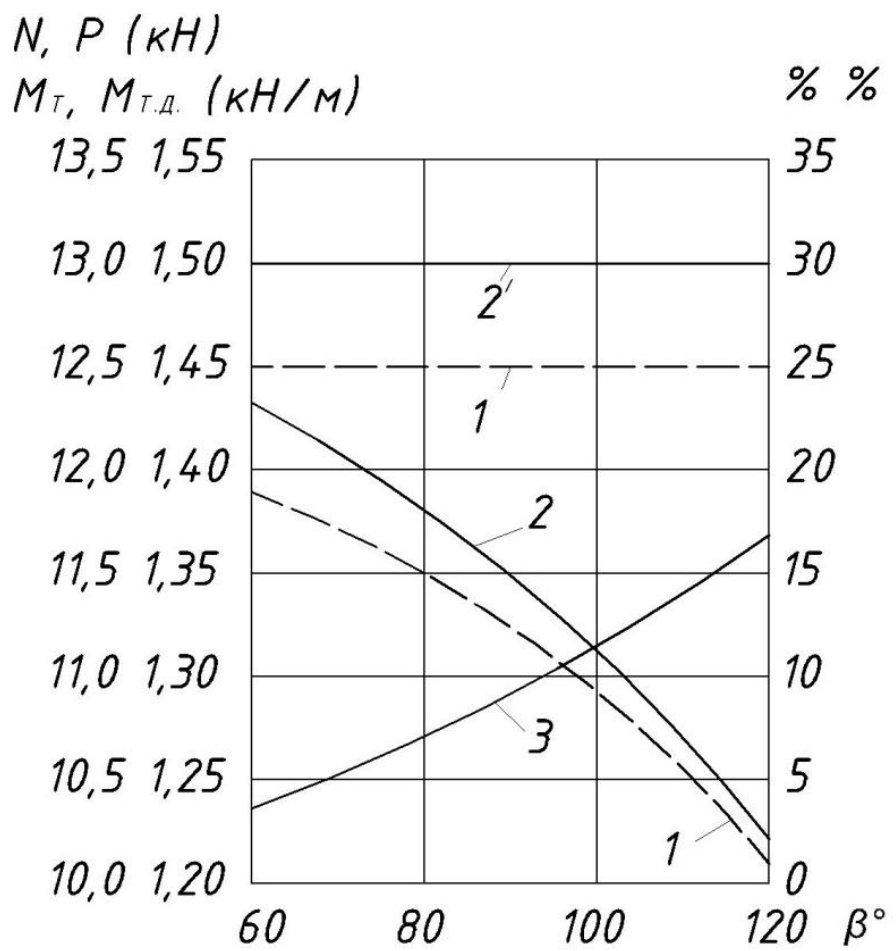

Рис. 3. Залежність від кута обхвату колодкою гальмівного шківа:

1, 1 '- нормативної і пропонованої величин притиснення колодки;

2, 2 '- нормативної і пропонованої величини гальмівного моменту;

3 - процентне розбіжність між моментами.

3. Не менш широкого поширення набули і стрічково-колодкові гальма [5, 6] в яких колодки притискаються до гальмівного шківа за допомогою стрічки.

Надалі розглянемо абсолютно жорстку на згин колодку, оскільки ця задача є аналогом завдань розглянутих вище. 3 урахуванням не абсолютно жорсткої колодки завдання розглянуто в [2].

Спочатку розглянемо одну колодку, оскільки порівняння формули (4) 3 нормативною, показує їх істотну різницю як у результатах розрахунків, так і в написанні.

Будемо вважати, що стрічка має натяг набігаючої вітки $S_{H}$, а збігаючої $S_{C}$. Якщо припустити, що в силовому трикутнику, який визначає тиск на гальмівний шків силами $S_{H}$ i $S_{C}$, різниця в кутах між ними незначна, то тиск на шків складе (рис. 4):

$$
P=\left(S_{H}+S_{C}\right) \cdot \cos \beta / 2 \text {. }
$$

Оскільки $M_{T д}=\left(S_{H}-S_{C}\right) R$, то відповідно до формули (4): 


$$
\frac{S_{H}}{S_{C}}=\frac{\beta+2 \cdot f \cdot \sin \frac{\beta}{2} \cdot \cos \frac{\beta}{2}}{\beta-2 \cdot f \cdot \sin \frac{\beta}{2} \cdot \cos \frac{\beta}{2}}=\frac{1+\frac{f}{\beta} \cdot \sin \beta}{1-\frac{f}{\beta} \cdot \sin \beta} .
$$

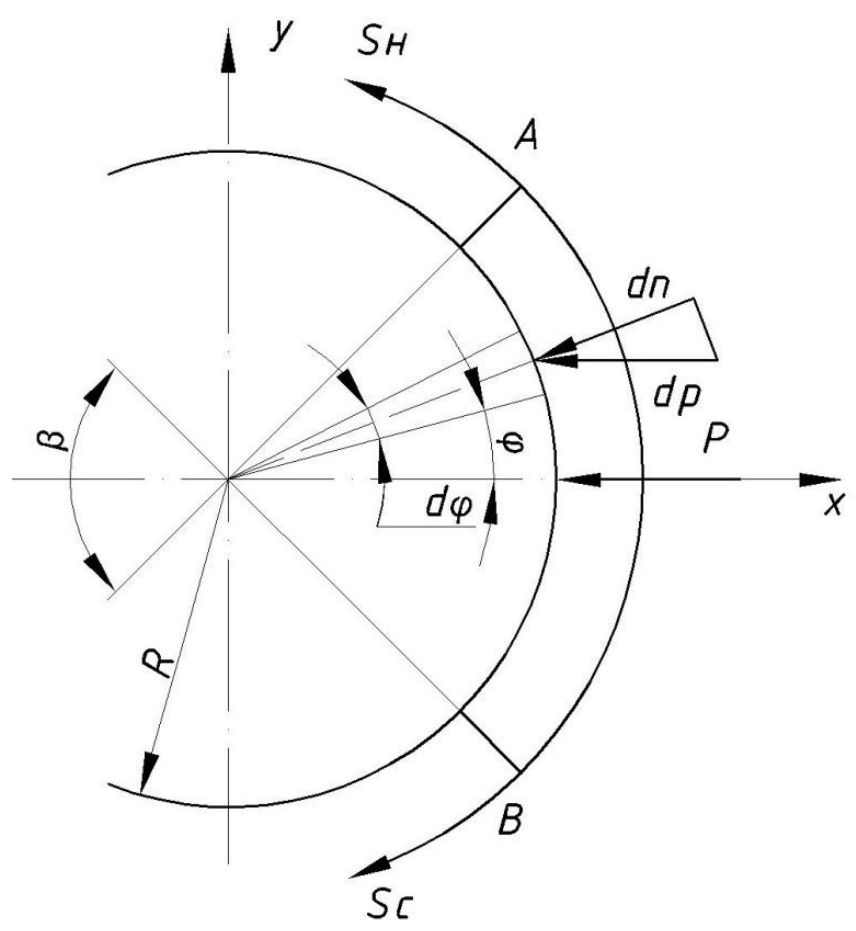

Рис. 4. Розрахункова схема стрічково-колодкового гальма (одна колодка).

На рис. 5 показані залежності $S_{H} / S_{C}$ від кута $\beta$, отримані за формулою (6) і для порівняння ці ж залежності для гнучкої нерозтяжної нитки (по Ейлеру).

$$
S_{H} / S_{C}
$$

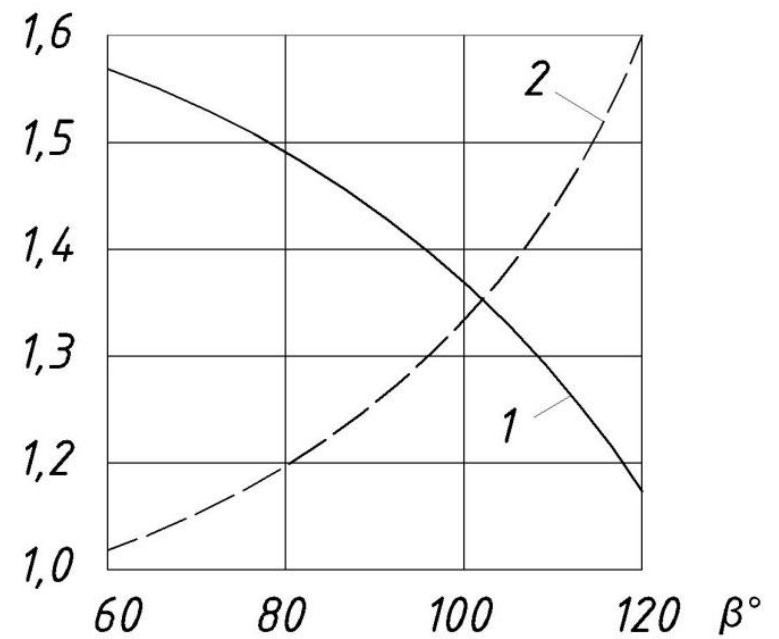

Рис. 5. Залежність $S_{H} / S_{C}$ від кута обхвату шківа:

1 - колодкою, що притискається стрічкою (6);

2 - гнучкою нерозтяжною ниткою (по Ейлеру).

Формула (6) при малому куті $\beta$ набуває вигляду:

або

$$
\frac{S_{H}}{S_{C}}=\frac{1+f}{1-f},
$$

$$
f=\frac{s_{H}-s_{C}}{s_{H}+s_{C}} .
$$


Аналіз отриманих залежностей і графіків на рис. 3 і рис. 5 дозволяє зробити наступні висновки і пропозиції.

1.Нормативна формула для визначення гальмівного моменту колодкового гальма відповідає притисненню двох площин і не враховує того, що нормальний тиск колодки на шків не дорівнює тиску на колодку.

2.В стрічково-колодкових гальмах при абсолютно жорсткій на згин колодці необхідно враховувати кут обхвату колодкою шківа при куті $\sin (\beta / 2) \approx \beta / 2$.

3.Нормативна величина гальмівного моменту, наприклад, при куті обхвату колодкою $80^{\circ}$, менше реального приблизно на $7 \%$.

4.Відношення натягів між набігаючою і збігаючою вітками стрічково-колодкового гальма залежить від кута охоплення колодкою шківа, наприклад, при куті $20^{\circ}$, різниця становить близько 30\% у порівнянні з величиною, отриманою без урахування абсолютної жорсткості колодки.

\section{Література}

1.Теоретическая механика в примерах и задачах. Т.2/Бать М.И., Джанелидзе Г.Ю., Кельзон А.С. - М.: Накеа, 1965. - 624c.

2.Довідник з опору матеріалів / Писаренко Г.С., Матвєєв В.В., Яковлев А.П. - К .: наук. думка, 1988. - 736с.

3.Справочник по кранам. В 2 т. Т.2/Александров М.Л., Гохберг М.М., Ковин А.А. и др. Л.: Машиностроение, 1988. - 559c.

4.Тормозные устройства. Справочник/ Александров М.П., Лысяков А.Г., Федосеев В.Н. и др. - М.: Машиностроение, 1985. - 319с.

5.Крижанівський Є.І., Вольченко М.О., Вольченко Д.О., Пургал М.П. Стрічковоколодкові гальма. - Івано-Франківськ: ІФНТУНГ, 2004. - 230с.

6.Бондаренко Л.Н. Определение средних радиусов трения конических и дисковых тормозов/ Подъемные сооружения. Специальная техника. - Одесса: НТА «Подъемные сооружения», 2009. - № 5(93). - С. $26-28$.

Драган А.П., Гороть Е.В.

ОП НУБиП Украины «Бережанский агротехнический институт»

\section{ДАВЛЕНИЕ КОЛОДОК НА ТОРМОЗНОЙ ШКИВ В КОЛОДОЧНЫХ И ЛЕНТОЧНО-КОЛОДОЧНЫХ ТОРМОЗАХ}

В данной статье проведено уточнение величины нормальных давлений колодки на тормозной шкив и, следовательно, величину тормозного момента колодочных и ленточноколодочных тормозов. Получено уравнение для определения тормозного момента для различных видов тормозов и проведено сравнение результатов расчета тормозного момента полученных по нормативным формулам и по формулам полученным в результате проведенных исследований.

Ключевые слова: колодочный тормоз, тормозной шкив, тормозной момент.

Drahan A.P., Horot E.V.

Separated Subdivision of National University of Life and Environmental Sciences of Ukraine «Berezhany agrotechnical institute»

\section{THE PRESSURE OF THE PADS ON THE BRAKE PULLEY IN THE PANEL AND BELT PADS BRAKES}

In this article, the specification of the magnitude of the normal pressure pads on the brake pulley and, consequently, the magnitude of the braking moment of shoe and tape and shoe brakes. An equation was obtained for determining the braking torque for various types of brakes and a comparison was made of the calculation results for the braking torque obtained using standard formulas and formulas obtained as a result of the studies performed.

Keywords: shoe brake, brake pulley, braking torque. 